\title{
TESTING COGNITIVE GADGETS
}

\author{
Cecilia Heyes \\ All Souls College \& Department of Experimental Psychology \\ University of Oxford \\ Oxford, OX1 4AL \\ cecilia.heyes@all-souls.ox.ac.uk
}

\begin{abstract}
Cognitive Gadgets is a book about the cultural evolution of distinctively human cognitive mechanisms. Responding to commentators with different and broader interests, I argue that intelligent design has been more important in the formation of grist (technologies, practices, ideas) than of mills (cognitive mechanisms), and that embracing genetic accommodation would leave research on the origins of human cognition empirically unconstrained. I also underline the need to assess empirical methods; query the value of theories that merely accommodate existing data; and ask whether acquiring literacy is more laborious than learning to imitate, to talk and to read minds.
\end{abstract}

\section{Keywords}

Cognitive gadgets; cognitive mechanisms; cultural evolution; evolutionary psychology; genetic accommodation; nativism 
Cognitive Gadgets (Heyes, 2018) is a new car ready for inspection. She is built not for haulage, speed or glamour, but to hold the road under difficult driving conditions. When Morin comes to the forecourt he examines Cognitive Gadgets with great care before taking her for a spin. There is, he finds, much to admire in the engine and body work, but the test drive is disappointing. Cognitive Gadgets won't take him where he wants to go, she is built for different roads. Dor, Ginsburg and Jablonka arrive as a lively, knowledgeable group. Like Morin, they find some features attractive the basic design of cultural evolutionary psychology is pleasing, and the trim stylish - but, for them, Cognitive Gadgets just isn't big enough. They need eight seats, ample luggage space, and a roof rack. Finally, Roige and Carruthers come by. They didn't expect to like Cognitive Gadgets and their worst suspicions are confirmed at a glance. This new car is not their old car, so it must be defective.

As the designer of Cognitive Gadgets, I am grateful to all six potential buyers for kicking the tyres. Here I will respond to each review in turn, highlighting some of the remarks I found most original and provocative. A recurrent theme will be the importance of making ideas about the evolution of human cognition "hold the road" - rooting them in, and making them testable by, empirical data from cognitive science.

\section{Morin: Different roads}

Morin's essay contains so many well-informed and perceptive comments that I feel sure the misunderstandings are my fault. (For example, I do not regard imitation as "the epitome of cultural learning", and I do not think that cognitive gadgets have been selected solely for their roles in cultural inheritance.) I am particularly grateful to Morin for taking the time to look at my backcatalogue. In the mirror of Roige and Carruthers' commentary I see an upstart who drafted Cognitive Gadgets with an empty head, then scrabbled to find arguments and evidence to shore up her flimsy ideas. In the Morin mirror I see someone who, for good or ill, has been moving towards a book like Cognitive Gadgets for decades, advancing more cautious versions of the same thesis, and 
testing them against empirical work from her own lab and elsewhere. I also enjoyed Morin's devices. I will respond using three of them: the juxtaposition of mindreading with puberty, the idea that Cognitive Gadgets is two books in one, and the deliciously crazy vision of Morin as a Texan creationist.

I can be swift on puberty. The evidence that girls with absent fathers reach menarche earlier than other girls (Boynton-Jarrett \& Harville, 2012) is an example of how culture - very broadly construed, to encompass any aspect of a child's social environment - can bring forward the onset of endocrinological change. Learning to read is a process in which culture - narrowly construed, as socially inherited information - constructs a cognitive system from old parts, determining how, when, and in what order various functions come on-line. Morin alleges that Cognitive Gadgets "gives us no reason to think [mindreading] is closer to literacy than to puberty" (p6). On the contrary, Cognitive Gadgets discusses a wealth of evidence from developmental, comparative and cross-cultural psychology that the development of mindreading (cognitive change) depends on socially inherited information (culture narrowly construed), and that this information determines, not only when, but how and in what order various mindreading functions come on-line. To clarify: in acknowledging that "mindreading may be a human universal" (p.6), I am embracing the idea that all human societies have cognitive resources dedicated to predicting, explaining and regulating behaviour. The evidence suggests that in some cases these have little in common with WEIRD belief-desire psychology (Henrich, Heine \& Norenzayan, 2010; Lillard, 1998). Indeed, in some cases the contrast between different mindreading systems may be as great as the contrast between contemporary descendants of the original Mesopotamian and Chinese writing systems.

Did I write two books in one? It is a neat idea, and in some ways flattering, but I do not think I did. I wrote one book on a topic that Morin does not find especially interesting - the origins of distinctively human cognitive mechanisms. However, I included discussions of cultural evolution, mostly at the beginning and end, which Morin hoped to apply to what he cares about - the stability of "traditions", sets of practices, artefacts and ideas (Morin, 2016). He is interested in "grist", what 
we do and make, and the contents of thought (e.g. writing systems, exogamy, radioactivity, electricity), whereas I am interested in "mills", the way our minds work (e.g. the computational mechanisms that enable us to read print, learn selectively from others, imitate, read minds, and speak to one another). He is interested in durability, why some traditions last longer than others, whereas I am interested in adaptedness, why some cognitive mechanisms do their jobs better than others. Morin wants narrative theory, a sequence and chronology of key events in human evolution, whereas Cognitive Gadgets offers force theory, an account of the processes involved in human evolution. Given these three differences, it is hardly surprising that Morin found his test drive disappointing. Cognitive Gadgets is not built for the roads he wants to travel. His roads are sound. they head in interesting directions (Buskell, 2017), just not in the directions I want to go. Cognitive Gadgets contains "positive claims" (p.2) in every chapter but they are about the evolutionary and developmental processes shaping adaptive, distinctively human cognitive mechanisms, not about the historical origins of durable human behavioural and intellectual traditions.

Although our purposes are fundamentally different, I think it is worth looking at the core issue raised by Morin's Texan creationist: Does Cognitive Gadgets assign too much importance to selection, rather than intelligent design, in the cultural evolution of distinctively human cognitive mechanisms? In pursuing this question, we can set aside Morin's concerns about my discussion of cultural group selection. I doubt that "modern history [reflects] the conditions that prevailed in our evolutionary past", and I do not merely "flirt" with a broader conception of cultural group selection than Morin's own, I am committed to a broader conception. In other words, I take both of his "options" (pp 9-10). However, since I am not an expert on cultural group selection, detailed study of our differences is unlikely to be helpful. Instead, let us focus on the distinction, which Morin and I both consider to be important, between cultural selection - any kind of cultural selection - and intelligent design.

Here, baldly stated, is my argument to the conclusion that distinctively human cognitive mechanisms have been shaped by cultural selection: These mechanisms, which are typical of the 
human species (by definition), do their jobs reasonably well, i.e. there is an adaptive fit between the way they operate and the cognitive tasks facing contemporary humans. We know of three sources of adaptive fit between a species-typical trait and its environment - genetic selection, intelligent design, and cultural selection (Dennett, 2017). Genetic selection is the option backed by High Church evolutionary psychology, but contemporary evidence from cognitive science, reviewed in Cognitive Gadgets, is not consistent with the idea that genetic selection is the principal architect of the human mind. Intelligent design now contributes to the development of some distinctively human cognitive mechanisms (e.g. there are education programmes designed to promote literacy), but it is not a plausible candidate for most of these mechanisms (e.g. mindreading, imitation). Therefore, to the extent that distinctively human cognitive mechanisms are adaptive - do their jobs well - it must be because they have been shaped by the third designer, cultural selection.

I do not think this is a "metaphysical" view (Morin, p 14), and I am not persuaded by Morin's arguments for intelligent design of distinctively human cognitive mechanisms. Yes, individuals and groups of people try to build things like boats and engines, physical technology, and "Cultural history abounds with cases where an invention process was concentrated in a few minds: radioactivity, blood circulation, electricity", but these are all examples of grist, not mills. I know of no reason to believe that anyone has ever tried to build a cognitive system capable of selective social learning, imitation or mindreading; to design education programmes specifically to establish and enhance these capacities. If such programmes exist, and if they work (it is one thing to try, and another to succeed), I would accept that intelligent design is likely to play a larger role, and cultural selection a smaller role, than I suggested in Cognitive Gadgets. In the meantime, in a showdown with the Texan creationist, I'm sticking to my guns.

\section{Dor, Ginsburg and Jablonka: Scope and capacity}

Cognitive Gadgets was written primarily for cognitive scientists, many of whom regard evolutionary psychology as a bad joke. It was designed to show that High Church evolutionary psychology is not 
the only game in town. It is possible to enquire about the evolutionary origins of human cognition without crude genetic determinism, fanciful storytelling, or an obsession with mate choice. This is a caricature of standard evolutionary psychology, which is grossly unfair both to the originators and to many contemporary exponents, but it is the picture I find in the eyes of many colleagues. I wanted to show them that computationalism can be combined with evolutionary analysis in a way that avoids these pitfalls and, crucially, has a better grip on current data from cognitive science. With that purpose in mind, I made the book short, because people who run labs do not have much time for books, and I gave it bold lines, such as the gadget/instinct and grist/mill distinctions, so that the contrasts with old-style evolutionary psychology would be clear.

Dor, Ginsburg and Jablonka have a different, much broader agenda (e.g. Avital \& Jablonka, 2000; Jablonka \& Lamb, 2014; Ginsburg \& Jablonka, 2010). Their impressive work is central to the development of a whole new framework for the understanding of evolution, a framework encompassing all organisms and all types of phenotypic trait - molecular, morphological, physiological, behavioural, and cognitive. They are revolutionaries with wide horizons who would have liked Cognitive Gadgets to be big enough - in size, ambition, and erudition - to include consideration of, inter alia: drift, assortative mating and guided variation in addition to selection; how associative learning may have changed since our common ancestor with the goldfish; their own "instruction of imagination" theory of language evolution; and changes in neuroanatomy and gene expression in the primate line which might one day, but do not yet, tell us more about the psychological starter kit for human cognition. Cognitive Gadgets might be a better book if it included all these things but, as far as I can tell, Dor and colleagues are not claiming that it would tell a fundamentally different story. For example, to focus on selection as a source of adaptive fit is not to deny the importance of other drivers of evolutionary change, and I did not claim to provide an exhaustive starter kit for human cognition. I am open to the idea that the starter kit includes additional motivational, attentional, and domain-general cognitive resources, and interested in the suggestion that it includes a psychological version of the blush. (Note that blushing is a behaviour, 
and therefore, like features of neuroanatomy and neurophysiology, it can't get in to the starter kit all by itself, only as a smoking gun for a genetically inherited psychological characteristic.) What would change my story about the starter kit is evidence that humans genetically inherit specific predispositions for the development of domain-specific cognitive mechanisms, and Dor et al. did not put forward evidence of that kind.

Yet more radical change to my story would be wrought by embracing the concept of genetic accommodation. "Genetic accommodation is gene-frequency change due to selection on the regulation, form or side effects of a novel trait" (West-Eberhard, 2003). In principle, the novel trait can be induced environmentally or by genetic change, and the processes of genetic accommodation can increase, decrease, or leave unchanged the extent to which development of the trait is sensitive to environmental factors. When genetic accommodation decreases sensitivity - i.e. when it reduces plasticity, or results in greater canalisation - it is called 'genetic assimilation'.

As the essay by Dor and colleagues illustrates, embracing the concept of genetic accommodation makes it possible to detect the footprint of gene-culture co-evolution everywhere in human cognition. This is because, to apply genetic accommodation to human cognition, one must fly blind - without relevant empirical examples or ground rules. West-Eberhard makes a compelling logical case for the occurrence of genetic accommodation but, as far as I can gather, the evidence is still sketchy and relates to morphological traits (e.g. size, number of wings, length of anal papillae) in plants, flies and honeybees. It appears that there are no empirical examples of the genetic accommodation of behavioural traits in mammals, let alone cognitive traits in primates, and it is not clear when one should and should not expect genetic accommodation of cognitive change to occur, or when it is likely to increase rather than decrease plasticity. Applying genetic accommodation to human cognition, at this stage in the concept's development, is an empirically unconstrained exercise, and therefore at odds with one of the central purposes of Cognitive Gadgets: to make ideas about the evolution of human cognition bite on data from cognitive science. One day that may be possible while embracing the concept of genetic accommodation, but not yet. 
So, I am resisting genetic accommodation as a guiding principle for those interested in the evolution of human cognition, but I am not against all forms of gene-culture co-evolution. If one assumes (uncontroversially) that genetic assimilation reduces plasticity, it is possible to test hypotheses suggesting that language, imitation and other cognitive gadgets have been genetically assimilated. So far, I have not found compelling evidence in support of such hypotheses, but I do not want to claim that the genetic assimilation of cognitive gadgets never happens. Similarly, although I do not say in Cognitive Gadgets that the accumulation of cultural grist is likely to have been a source of selection pressure for the starter kit (Dor et al are right to challenge me on that), I have no problem with the idea that gene-culture co-evolution contributed to the expansion of domaingeneral cognitive resources in the hominin line.

\section{Roige and Carruthers: Standards of evidence}

My explanatory targets are different from those of Morin and Dor et al., but Roige, Carruthers and I have common cause - like them, I am trying to explain the origins of distinctively human cognitive mechanisms within a fairly standard evolutionary framework.

Answers to many of the objections raised by Roige and Carruthers can be found in Cognitive Gadgets or in my response to commentaries in The Behavioral and Brain Sciences (Heyes, in press a \& b). For example, attentive readers will discover in the book itself that I do not advance a "Hebbian" view of imitation (Cooper, Cook, Dickinson \& Heyes, 2013); I do not regard associative learning as the "only cognitive resource"; and, although I did not addressed Carruthers' theory specifically, I am keenly aware that crucial issues in the debate about the evolution of human cognition are "the starting-state of development and the nature of the systems that enable learning". Chapter 3 of Cognitive Gadgets advances and defends my account of the "Starter Kit" for distinctively human cognition, and Chapters 4-8 - on "Cultural Learning", "Selective Social Learning", "Imitation", "Mindreading" and "Language" - are devoted to discussion of the "nature of the systems that enable learning" and how those systems are themselves learned. So, instead of 
digging-over old ground, I want to focus on three broadly methodological issues that may help to explain why my thinking about the "starting-state" and "systems that enable learning" is so different from that of Roige and Carruthers.

First, we seem to have different approaches to evidence. There is so much empirical work relevant to the evolution of human cognition - from comparative, cross-cultural, developmental, experimental, moral and social psychology, cognitive neuroscience, and behavioural economics, among other fields - that it is tempting to focus on the headlines and take authors at their word. If an article appears in a high-impact journal, such as those in the Nature and Science groups, and if the abstract says "we found X", it's tempting for those of us with interests that span many empirical specialities to accept that "they found X" and move on. But, in my (irritating) opinion, this just won't do. As indicated by the San Francisco Declaration on Research Assessment (DORA), and even by Clarivate Analytics, the company that calculates impact factors, the impact of a journal is not a reliable guide to the quality of any given article published in that journal, and it is well-known that the incentive structures of contemporary science discourage authors from giving coolly descriptive accounts of what their results show. Consequently, before trusting the headlines, and adopting $X$ as a constraint on theorising, we need to look closely at experimental and statistical methods.

Consider as an example the study by Simpson et al. (2016) which plays a prominent role in Roige and Carruthers' case for the innateness of human imitation. The headline of this study, published in a Nature journal, is that macaque monkeys are capable of facial gesture imitation in the first week of life, but the methods fall well short of justifying that conclusion. It has been known for more than 40 years that to detect imitation reliably it is necessary (although not sufficient) to use a "cross-target" procedure in which at least two actions are observed and measured (Meltzoff \& Moore, 1977). If you find that, for example, infants are more likely to open their mouths than to protrude their lips after seeing mouth opening, and more likely to protrude their lips than to open their mouths after seeing lip protrusion, there is a fighting chance that the infants were imitating mouth opening and/or lip protrusion. But Simpson et al. presented and measured just one action - 
lip-smacking. They found that some neonatal monkeys smack their lips more after seeing a human lip-smacking than after seeing a coloured disc rotating. Given that the disc was an inanimate rather than a social stimulus, and that lip-smacking is a lets-be-friendly social gesture (Fedurek et al, 2015), the most likely explanation for this result is that the monkeys, who had been taken from their mothers at birth and housed in social isolation, were doing everything they could to make and prolong social contact with the experimenter. Desperate for contact, it is likely that they did a whole range of things more after the social than the inanimate stimulus - wriggling, vocalising, blinking and that they would have behaved the same way regardless of what the experimenter was doing with his face. In short, the study at the heart of Roige and Carruthers case for the innateness of imitation does not come close to demonstrating a selective tendency to respond to lip-smacking with lip-smacking.

Second, unlike Roige and Carruthers, I value prediction over accommodation. They say that “An innate learning-system account [such as Carruthers' own] can of course accommodate the evidence of learning that Heyes appeals to in support of her cognitive-gadgets view". Let us suppose this is true, because it seems to me that at some level it must be true. In Cognitive Gadgets I suggested that - due to the labile nature of Chomskyian theory, and pernicious effects of the competence-performance distinction - research on the evolution and development of language may have reached a point where key questions cannot be resolved by empirical means. In contrast, I assumed that the other research fields on which I was drawing - for information about attentional biases, social motivation, imitation, mindreading etc - remain healthy; that the intellectual resources and social practices of these fields are still such that inference to the best explanation can win the day. Even if this assumption is correct, it would be Pollyannaish to deny that, in principle, all the data I marshalled in Cognitive Gadgets could be accommodated by an "innate learning-system" account. Given that theories about the evolution of human cognition are informal rather than mathematical, and that standards of evidence are not uniform (see above), this kind of accommodation must be possible, but is it plausible? The answer depends on many considerations 
but, for me, prediction is one of the most important. I find consistency with evidence I did not know about when formulating my hypotheses, and confirmation of novel predictions, much more persuasive than a fit between theory and the data it was designed to accommodate. When specific explanatory targets are visible, we find it all-but impossible to resist "fudging" (Lipton, 2003).

That is why I always try to make my gadget hypotheses generate novel predictions. When I ran a lab, many of them were tested, and confirmed, by my own research group. Now I publish the predictions along with the hypotheses and suggest specific experimental strategies for testing them. Roige and Carruthers cited a study of false belief understanding in chimpanzees, by Kano et al. (2017), inspired by one of these suggestions. Unfortunately, as I told Kano and colleagues before they ran the study (correspondence available with their consent), their stimuli were not controlled in the way I had proposed (Heyes, 2014; 2017), and therefore the results are not interpretable. However, by my lights all attempts to test novel predictions, including those of Kano et al., are very welcome; they are the rutted road to scientific progress.

Finally, I want to reflect briefly on an assertion made by Roige and Carruthers at the beginning of their commentary and echoed in Morin's essay: Learning to read print is difficult, but learning to imitate, to talk, and to read minds is easy - children "do so early, easily, and in the absence of explicit instruction". This remark ignores the evidence, surveyed in Cognitive Gadgets, that imitation and mindreading come on-line much later than is claimed by contemporary nativists, and that learning to talk and to read minds involves a good deal of instruction. Nonetheless, I think Roige and Carruthers are on to something here. Even when one studies the evidence of late development and everyday instruction, the intuition remains (I still have it) that, while learning to read print is a laborious business, learning to imitate, talk and read minds is like falling off a log.

Why? What makes this intuition so stubborn? My hunch is that there are two related reasons. First, for most people, learning to imitate, talk and read minds is a good deal more enjoyable than learning to read print, and we mistakenly assume that, when children are enjoying themselves, their cognitive systems are not working hard. We learn to imitate, talk and read minds 
in the context of spontaneous social interaction, the kind of interaction in which children enjoy the pleasures of having effects, taking turns, and being understood. In contrast, in most contemporary societies, literacy training occurs under conditions of constraint, in schools where children are away from their homes and families. Even in the early stages, when children are Reading With Mother, efforts to teach reading often supplant more enjoyable activities such as simply listening to a story. Second, lacking clear concepts of proficiency, and appropriate methods of measurement, we overestimate how skilled most of us become as imitators, talkers and mindreaders. We assume, wrongly, that everyone gets to be an expert. There are whole technologies devoted to the measurement of literacy, technologies that enable educators and employers to determine exactly how far children have progressed along the road to literacy, and where adults have stopped on that road (e.g. Castles et al., 2009; Friedmann \& Coltheart, 2015). In contrast, as far as I know, there is not a single standardised test of proficiency in imitation for typical adults (neurologically intact, of average intelligence, and without a developmental disorder such as autism); many tests of talking are tied up with literacy or given only to a small, highly education slice of the population; and the widely used, and therefore familiar, tests of mindreading assess one or a small number of components of the whole competence - for example, the capacity to attribute false beliefs, or to distinguish knowledge from ignorance. Consequently, when it comes to imitation, talking and mindreading - but not print reading - we are free to assume that everyone reaches a high level of attainment. I predict that, as we develop better concepts and measures of proficiency, we will find that levels of attainment are in fact highly variable.

At present, most of the evidence behind this prediction is anecdotal. At dance and exercise classes, there is often a blushing novice who, although their spontaneous movements are wellcoordinated, seems incapable of imitating the instructor. In conversation, especially among strangers, who has not been struck by the mindreadingless insensitivity of some people who seem otherwise to be friendly and intelligent? But there are also some preliminary data behind the prediction. For example, testing people from various educational backgrounds (not just college 
sophomores), Dabrowska (2012) has documented marked variation among "normal" individuals in the grammatical rules applied when producing and hearing their native language. Similarly, use of the Movie to Assess Social Cognition (MASC, Dziobek et al. 2006), is beginning to reveal marked variation in mindreading proficiency even among the adults - typically university students - who volunteer to participate in psychological research (Conway et al., in press). The MASC introduces four characters and shows them chatting, cooking, eating and playing a board game as they spend an evening together. Every few minutes, the action stops and viewers are asked a multiple-choice question about a character's thoughts and feelings, for example, "Why did Sandra say that?". In this test, which captures the full demands of mindreading in everyday life, the performance of typical adults varied from $40-93 \%$ correct. I predict that, when variation of this kind has been more fully documented and explained, we will kick the intuition that learning to imitate, talk and read minds demands less cognitive labour than learning to read print.

\section{Conclusion}

I am glad that Cognitive Gadgets has been tested by Morin, Dor et al., and Roige and Carruthers. Although Morin and Dor et al. have very different purposes - compared with me and with each other - all three essays highlighted key issues in research on the evolution of human cognition. Morin's essay draws attention to the gap between grist and mills. Changes over time in technologies (e.g. writing systems), practices (e.g. exogamy), and ideas (e.g. electricity), although they may be themselves products of cultural evolution, cannot be identified with changes in underlying cognitive mechanisms. Grist change can provide clues to mill change, but the evolutionary dynamics are likely to be very different in the two cases. Specifically, the signs are that intelligent design has played a much more significant role in the evolution of grist than of mills.

The concerns expressed by Dor et al. remind us that major changes are afoot in evolutionary theory. Anyone working on a specific project, such as the evolution of human cognition, must decide whether to embrace radical new concepts such as genetic accommodation. I have taken a 
relatively conservative view because, as things stand, an evolutionary framework based on genetic accommodation would leave research on the origins of human cognition empirically unconstrained. I think that is the right decision, but I recognise that a well-founded argument could be made for prioritising breadth and synthesis over testability.

Finally, and inevitably given that their purposes are similar to mine, the objections raised by Roige and Carruthers highlight more specific methodological issues. To what extent can philosophers, and others who "consume" empirical research relevant to the evolution of cognition, use this research without scrutiny of experimental and statistical methods? What is the value of "intermediate-strength" theories about the evolution of human cognition, which accommodate existing data but do not make novel predictions that can be tested against alternative theories? And, most interesting in my view because it is an empirical question: Is it as easy as we imagine to upload cognitive gadgets?

\section{Acknowledgements}

I am grateful to Jonathan Birch, Geoff Bird and Max Coltheart for their advice while I was writing this response. 


\section{References}

Avital, E., \& Jablonka, E. (2000). Animal traditions: Behavioural inheritance in evolution. Cambridge: Cambridge University Press.

Boynton-Jarrett, R., \& Harville, E. W. (2012). A prospective study of childhood social hardships and age at menarche. Annals of Epidemiology, 22, 731-737.

Buskell, A. (2017). Cultural attractor theory and explanation. Philosophy, Theory, and Practice in Biology, 9, 13.

Castles, A., Coltheart, M., Larsen, L., Jones, P., Saunders, S. \& McArthur, G. (2009). Assessing the basic components of reading: A revision of the Castles and Coltheart test with new norms. Australian Journal of Learning Difficulties, 14, 67-88.

Conway, J. R., Coll, M-P., Koletsi, S., Bronitt, N., Catmur, C. \& Bird, G. (in press). Understanding how minds vary relates to skill in inferring mental states, personality, and intelligence. Journal of Experimental Psychology: General.

Cooper, R. P., Cook, R., Dickinson, A., \& Heyes, C. M. (2013). Associative (not Hebbian) learning and the mirror neuron system. Neuroscience Letters, 540, 28-36.

Dąbrowska, E. (2012). Different speakers, different grammars: Individual differences in native language attainment. Linguistic Approaches to Bilingualism, 2, 219-253. 
Dennett, D. C. (2017). From Bacteria to Bach and Back: The Evolution of Minds. WW Norton \& Company.

Dziobek, I., Fleck, S., Kalbe, E., Rogers, K., Hassenstab, J., Brand, M., ... \& Convit, A. (2006). Introducing MASC: a movie for the assessment of social cognition. Journal of Autism and Developmental Disorders, 36, 623-636.

Fedurek, P., Slocombe, K. E., Hartel, J. A., \& Zuberbühler, K. (2015). Chimpanzee lip-smacking facilitates cooperative behaviour. Scientific Reports, 5, 13460.

Friedmann, N., \& Coltheart, M. (2015). Types of developmental dyslexia. In Bar-On, A. \& Ravid, D. (Eds.), Handbook of Communication Disorders: Theoretical, Empirical and Applied Linguistics Perspectives. Berlin, Boston: De Gruyter Mouton.

Ginsburg, S., \& Jablonka, E. (2010). The evolution of associative learning: A factor in the Cambrian explosion. Journal of Theoretical Biology, 266, 11-20.

Henrich, J., Heine, S. J., \& Norenzayan, A. (2010). The weirdest people in the world? Behavioral and Brain Sciences, 33, 61-83.

Heyes, C. M. (2014). False belief in infancy: a fresh look. Developmental Science, 17, 647-659.

Heyes, C. M. (2017). Apes submentalise. Trends in Cognitive Sciences, 21, 1-2.

Heyes, C. M. (2018). Cognitive Gadgets: The Cultural Evolution of Thinking. Cambridge, MA: Harvard University Press. 
Heyes, C. M. (in press a). Precis of Cognitive Gadgets: The Cultural Evolution of Thinking. Behavioral and Brain Sciences.

Heyes, C. M. (in press b). Cognitive blindness and cognitive gadgets. Behavioral and Brain Sciences.

Jablonka, E., \& Lamb, M. J. (2014). Evolution in Four Dimensions: Genetic, Epigenetic, Behavioral, and Symbolic Variation in the History of Life. Revised edition. MIT press.

Kano, F., Krupenye, C., Hirata, S., Call, J., \& Tomasello, M. (2017). Submentalizing cannot explain belief-based action anticipation in apes. Trends in Cognitive Sciences, 21, 633-634.

Lillard, A. (1998). Ethnopsychologies: cultural variations in theories of mind. Psychological Bulletin, 123, 3-32.

Lipton, P. (2003). Inference to the Best Explanation. Routledge.

Meltzoff, A. N., \& Moore, M. K. (1977). Imitation of facial and manual gestures by human neonates. Science, 198, 75-78.

Morin, O. (2016). How Traditions Live and Die. Oxford: Oxford University Press.

Simpson, E., Miller, G., Ferrari, P., Suomi, S., \& Paukner, A. (2016). Neonatal imitation and early social experience predict gaze following abilities in infant monkeys. Nature Scientific Reports, 6, 20233.

West-Eberhard, M. J. (2003). Developmental Plasticity and Evolution. Oxford University Press. 